\title{
Integrated management strategies for chronic obstructive pulmonary disease
}

\author{
This article was published in the following Dove Press journal: \\ Journal of Multidisciplinary Healthcare \\ 18 September 2010 \\ Number of times this article has been viewed
}

\author{
David A Sonetti ${ }^{1,2}$ \\ Angela C Hospenthal ${ }^{2}$ \\ Sandra G Adams ${ }^{1,2}$ \\ 'Department of Medicine, Division \\ of Pulmonary Diseases/Critical Care \\ Medicine, The University of Texas \\ Health Science Center, San Antonio, \\ Texas, USA; ${ }^{2}$ South Texas Veterans \\ Health Care System, Audie L. Murphy \\ Division, San Antonio, Texas, USA
}

Correspondence: Sandra G Adams South Texas Veterans Health Care System, Audie L. Murphy Memorial Veterans Hospital, Pulmonary Diseases Section (I I IE), 7400 Merton Minter Blvd., San Antonio, TX 78229, USA

$\mathrm{Tel}+\mid$ 2l 0-6I7-5256

Fax + I 210-949-3006

Email adamssg@uthscsa.edu

\begin{abstract}
Chronic obstructive pulmonary disease (COPD) remains the fourth leading cause of death, is associated with significant morbidity and places a substantial time and cost burden on the health care system. Unfortunately, treatment for COPD remains underutilized and continues to focus on the acute care of complications. The chronic care model (CCM) shifts this focus from the acute management of symptoms and complications to the prevention and optimal management of the chronic disease. This model utilizes resources from the community and the health care system and emphasizes self-management, provides comprehensive clinic support, and implements evidence-based guidelines and technology into clinical practice to ensure delivery of the highest quality of care. The goal of this review is to use a case-based approach to provide practical information about how integrated care using the CCM can be applied to the clinical care of a complex patient with COPD, shifting the management goals for COPD from reactive to proactive and ultimately improving outcomes.
\end{abstract}

Keywords: lung disease, chronic obstructive integrated care, chronic care model, evidencebased guidelines

\section{Case history}

Mrs B is a 56-year-old Caucasian woman who presents to establish care with a primary care clinician after relocating to the area. She reports a long history of tobacco use, hypertension, and gout. Her previous doctor had recently diagnosed her with chronic obstructive pulmonary disease (COPD) and started her on treatment with albuterol and ipratropium nebulizers after she complained of worsening dyspnea and cough. Mrs B, however, believes that these symptoms are primarily related to her advancing age. Over the past year, she recalls three episodes of acute worsening of dyspnea in which one episode required hospitalization. On two of these occasions, she was forced to seek care at an urgent care facility because neither her primary clinician nor the clinic support staff could be reached in a timely manner for assistance. Her main concerns today are persistently cold hands over the past several months and worsening insomnia. The patient's husband adds that lately it seems to take his wife twice as long to finish anything around the house and that she appears more withdrawn, excusing herself from activities outside the house. He also states that she often falls asleep during the day, even during her favorite television show. On exam, the patient is 5 feet, 8 inches tall, weighs 104 pounds, and has a resting room air oxygen saturation of $82 \%$. She appears thin with a rounded, barrel-shaped chest. Heart sounds are distant and breath sounds are diminished with occasional wheezing. Extremities appear 
pale and are cool to palpation without evidence of clubbing. Chest radiograph shows hyperinflated lungs and osteopenic appearing ribs. Review of the patient's past medical records shows a postbronchodilator forced expiratory volume in one second $\left(\mathrm{FEV}_{1}\right)$ to forced vital capacity $(\mathrm{FVC})$ ratio of 0.58 $(58 \%)$ and an $\mathrm{FEV}_{1}$ of $35 \%$ predicted.

\section{Introduction}

COPD is a preventable and treatable disease characterized by progressive airflow limitation that is not fully reversible. ${ }^{1}$ Worldwide, COPD remains the leading cause of death from lung disease and the fourth leading cause of death overall. ${ }^{2}$ In the United States alone, yearly data show that COPD is responsible for at least eight million outpatient clinician encounters, 1.5 million emergency department visits, and 726,000 hospitalizations. ${ }^{3}$ Collectively, these hospitalizations represent over $65 \%$ of COPD-related costs. ${ }^{4}$ Unfortunately, COPD remains underdiagnosed and undertreated in both its early and late stages and is associated with multiple comorbidities. ${ }^{3,5}$ Historically, the medical community has focused on acute care and short-term goals. Emphasis was placed on the management of acute exacerbations and complications and speeding time to recovery. This "acute care model" encouraged patients to assume a passive role in the management of their disease and placed the bulk of responsibility for problem solving on the clinician. Unfortunately, this acute care model is broken and the Institute of Medicine reports that "the current care systems cannot do the job," "trying harder will not work," but "changing care systems will."

\section{The Chronic Care Model}

The Chronic Care Model (CCM) addresses these shortcomings by identifying essential elements that encourage high-quality chronic disease care. ${ }^{7-9}$ This model provides a multidisciplinary, organized approach to delivering care for patients with chronic diseases, which involves the community and the health care system and fosters communication between clinicians and well-informed patients. The goals of this model are to (1) improve chronic disease management, (2) facilitate the prevention of complications, and (3) improve outcomes, including health care utilization and quality of life. With implementation of at least one CCM element, improved clinical outcomes were demonstrated in a meta-analysis of data on a variety of chronic diseases including asthma and congestive heart failure. ${ }^{10}$ In COPD, a significant benefit in outcomes was also seen if at least two CCM elements were present. ${ }^{11,12}$ Benefits identified by these systematic reviews included reductions in unscheduled clinic and emergency room visits, frequency of hospitalizations, improved exercise capacity, and a shorter length of stay.

Components of the CCM include (1) self-management, (2) delivery system design, (3) decision support, and (4) clinical information systems (http://www.improvingchroniccare. org). Self-management focuses on education to foster patient's confidence and effort, thereby improving overall autonomy. This is accomplished not through lectures, but by using clinical scenarios in problem solving, skill development, and decision making. ${ }^{13}$ Community-based resources are relied on heavily for this component, including pulmonary rehabilitation programs, patient education materials, group classes, and ideally a home health case manager who can continuously assess difficulties as well as acknowledge accomplishments. A COPD "action plan" is probably the best known example of a self-management tool, but other effective interventions include medication compliance, proper inhaler technique, adequate nutrition, and regular exercise. ${ }^{14}$ To improve the quality of life in COPD patients, an "action plan" provides knowledge on COPD and its symptoms, suggests ways to control symptoms and maintain function, educates on the early recognition of acute exacerbations of COPD (AECOPD), and plans for treatment using self-initiated prescriptions. It also promotes exercise, sleep, nutrition, and leisure to improve mental health. ${ }^{14}$ Therefore, self-management is an important component of the CCM.

The other components of the CCM include the delivery system design, clinical information systems, and decision support. Well-trained clinical teams to ensure successful selfmanagement, coordinate preventive care, screen for common comorbid diseases, and address questions or acute issues around the clock are the key features of delivery system design. An active clinical information system provides automated reminders of practice guidelines as well as performance feedback to clinicians. Finally, the decision support component involves the use of evidence-based practice guidelines, which are critical to optimally managing any chronic illness. Effective management of complicated chronic diseases like COPD is best accomplished by clinicians working in collaboration, not isolation, with the assistance of a variety of health care resources.

\section{Diagnosing COPD}

However, guidelines cannot be applied to patients who do not yet have a diagnosis of COPD. Therefore, identifying patients with the disease is important. Dyspnea and chronic cough are the cardinal features of COPD. Cough, which may be nonproductive, is often the first symptom of COPD, but is often overlooked by patients and may be intermittent 
early in the disease course. ${ }^{15,16}$ There is typically a significant delay in the pursuit of medical care by patients with dyspnea, often waiting until symptoms affect the performance of activities of daily living. This reflects (1) the slow onset of COPD symptoms that allows for gradual and compensatory adjustments in lifestyle and (2) a tendency to subjectively minimize the degree of symptoms and/or redirect blame, most commonly attributing symptoms to advancing age. Wheezing and chest tightness are nonspecific symptoms and their absence does not exclude the diagnosis of COPD. ${ }^{17}$

The diagnosis of COPD requires spirometry to confirm the presence of airflow obstruction in any patient presenting with symptoms and/or risk factors concerning for COPD. ${ }^{15}$ Airflow obstruction in COPD is defined as a postbronchodilator $\mathrm{FEV}_{1}$ to $\mathrm{FVC}$ ratio of less than 0.70 $(70 \%) \cdot{ }^{15}$ Severity of the disease is then based on the degree of reduction in the postbronchodilator $\mathrm{FEV}_{1}$, but can sometimes be inferred by severe symptoms and presence of associated complications. The Global Initiative for Chronic Obstructive Lung Disease (GOLD) guidelines classify COPD as mild when the postbronchodilator $\mathrm{FEV}_{1}$ is greater than or equal to $80 \%$ predicted, moderate when $50 \% \leq \mathrm{FEV}_{1}<80 \%$ predicted, severe when $30 \% \leq \mathrm{FEV}_{1}<50 \%$ predicted, and very severe if $\mathrm{FEV}_{1}<30 \%$ predicted or $\mathrm{FEV}_{1}<50 \%$ predicted with the presence of chronic respiratory failure. ${ }^{6}$ Interestingly, $\mathrm{FEV}_{1}$ does not consistently predict disability or mortality in COPD. A better predictor of morbidity and mortality from COPD is the BODE index, which includes the body mass index (B), the degree of airflow obstruction (O), dyspnea (D), and exercise capacity (E), assessed by the 6-minute walk test. ${ }^{18}$

Asthma may be difficult to distinguish from COPD. Features that favor the diagnosis of asthma include largely reversible airflow limitation, significant daily variation in symptoms with a predominance of nocturnal or early morning symptoms, a family history of asthma, a history of "childhood asthma," age of onset of symptoms before 40 years old, minimal or no exposure to tobacco, and comorbid allergy or atopy. ${ }^{15}$ However, it is important to note that asthma can present in adulthood, some asthmatics smoke cigarettes, and asthma and COPD coexist in up to $10 \%-15 \%$ of patients; therefore, clinical judgment is necessary in defining patients with obstructive lung disease. Other diseases of airflow obstruction with dyspnea and cough include congestive heart failure, bronchiectasis, obliterative bronchiolitis, and a variety of pulmonary infections including tuberculosis. These alternative diagnoses are typically easily differentiated from COPD by history and imaging of the chest.
The leading risk factor for COPD remains cigarette smoking. ${ }^{19}$ Other risk factors include second-hand smoke, occupational dusts and chemicals, and indoor air pollution from biomass cooking and heating in poorly ventilated areas. ${ }^{20-22}$ The role of outdoor air pollution in the etiology of COPD is unclear..$^{15}$ The evidence-based GOLD guidelines emphasize that the most important and effective aspect of COPD management is smoking cessation., ${ }^{1,15}$ In an 11-year follow-up study, participants who continued to smoke saw an average yearly decline in $\mathrm{FEV}_{1}$ twice as great as ex-smokers. ${ }^{23}$ In addition, the rate of decline in lung function in ex-smokers did not differ significantly from never-smokers. A significant reduction in symptoms of cough, sputum production, wheezing, and shortness of breath is also seen in patients with COPD who quit smoking. ${ }^{24}$ All patients with COPD who continue to smoke should, therefore, receive help with smoking cessation, including counseling and potentially pharmacotherapy to achieve smoking abstinence. In addition, ex-smokers should be congratulated and reminded of the importance of remaining tobacco free.

\section{Evidence-based COPD treatment}

The GOLD guidelines recommend that symptomatic patients with COPD should be treated with bronchodilators. ${ }^{15}$ Current pharmacotherapy for COPD has been shown to decrease symptoms and complications, but does not help modify the clinical course including the decline in lung function or survival. In patients with mild COPD, short-acting bronchodilator therapy is recommended on an as-needed basis for relief of symptoms. ${ }^{15}$ Either a $\beta 2$-agonist (albuterol) or an anticholinergic (ipratropium bromide) can be used in this setting with the final choice reflecting patient response, preference, and medication availability. Combination shortacting bronchodilator therapy appears to provide additional benefit in $\mathrm{FEV}_{1}$ response..$^{25}$

Symptomatic patients with moderate to very severe COPD should be treated with one or more long-acting bronchodilators in addition to short-acting as-needed rescue inhaler(s). ${ }^{15} \mathrm{Of}$ note, a detailed history may be required to identify "symptomatic" patients, since many people with COPD slowly reduce their activity level and attribute their symptoms to "natural aging." Options for treatment with long-acting bronchodilators include the long-acting beta 2-agonists (LABA) salmeterol, formoterol, or arformoterol and the long-acting anticholinergic (LAAC) tiotropium. These long-acting bronchodilator agents have been shown to significantly improve lung function, quality of life, and reduce hyperinflation. ${ }^{15,26-28}$ There are no recommendations for which agent to start initially, but it is clear that long-acting bron- 
chodilators are superior and more effective, albeit also more expensive, than short-acting bronchodilators. ${ }^{15}$ One landmark trial (entitled Understanding Potential of Long-term Impacts on Function with Tiotropium [UPLIFT]) of nearly 6,000 subjects with COPD followed for 4 years evaluated tiotropium compared with placebo. ${ }^{27}$ Both groups also received "usual care," which included a LABA and/or inhaled corticosteroid therapy (ICS) in over $60 \%$ of subjects. The study did not achieve its primary end point of demonstrating a change in the rate of decline of $\mathrm{FEV}_{1}$. However, the tiotropium group had a sustained increase in lung function, a reduction in AECOPD, improved quality of life, and reduced cardiac morbidity. ${ }^{27}$

The GOLD guidelines recommend the addition of ICS to long-acting bronchodilator therapy only in patients with severe COPD and in those with repeated exacerbations. ${ }^{15}$ The ideal combination of bronchodilator and inhaled steroid therapy is not known. Another landmark study of over 6,000 subjects followed for 3 years (entitled TOwards a Revolution in COPD Health [TORCH]) evaluated the combination LABA and ICS (salmeterol/fluticasone), compared with each individual agent and placebo. This study also did not reach its primary end point of a reduction in mortality, with a $P$ value of 0.052 . However, it is thought that the actual effect on mortality may be underestimated due to the loss of sicker patients in the placebo group who dropped out of the study seeking active treatment. Similar to the improvements in the treatment group of the UPLIFT trial, the TORCH trial demonstrated a significant reduction in the frequency of exacerbations and improvement in quality of life and lung function in subjects treated with salmeterol/fluticasone combination therapy. ${ }^{28}$ Triple therapy with LABA, LAAC, and ICS has been shown to improve quality of life, lung function, and health care use when compared with LAAC alone or LAAC in combination with ICS. ${ }^{29}$ In contrast to the known benefits of these maintenance inhaled medications, the GOLD guidelines clearly state that there is no role for long-term oral glucocorticosteroids in COPD due to lack of significant benefits and the potential for serious side effects including cataracts, osteoporosis, and myopathy. ${ }^{15}$ In patients with severe COPD, steroid myopathy has been shown to decrease functionality and increase the risk of respiratory failure. ${ }^{30}$

Mucolytic therapy has been used for many years in an attempt to reduce sputum tenacity in patients with COPD despite controversy on whether changes in mucus viscosity alter cough effectiveness. ${ }^{31,32}$ In one of the best studies to date, a large randomized placebo-controlled trial of $\mathrm{N}$-acetylcysteine (NAC), no benefit in prevention of deterioration in lung function or prevention of exacerbations was seen. ${ }^{33}$ Subgroup analysis, however, suggested a decreased exacerbation rate in patients receiving NAC but not treated with ICS. A subsequent Cochrane meta-analysis which included this study and 27 other randomized controlled trials evaluating a variety of drugs concluded that mucolytic therapy was associated with a small reduction in the rate of acute exacerbations. ${ }^{34}$ According to the GOLD guidelines, "the overall benefits seem to be very small and widespread use of these agents cannot be recommended at present". ${ }^{15}$ It is also important to note that coughing serves to clear the airways of mucus due to excessive secretions or impaired mucociliary clearance and that suppression of this natural and protective reflex with antitussive therapy should generally be avoided in patients with COPD. ${ }^{35}$

A number of nonpharmacologic treatments for patients with COPD also improve outcomes, including pulmonary rehabilitation, supplemental oxygen in selected patients, vaccinations, and surgery. Pulmonary rehabilitation focuses on exercise conditioning, breathing retraining, psychosocial support, smoking cessation, and nutritional counseling. ${ }^{36}$ Pulmonary rehabilitation programs have recently seen tremendous growth in interest as additional supporting clinical data now clearly demonstrate reduced dyspnea, increased exercise tolerance, improved physical and emotional participation, and decreased health care costs. ${ }^{37}$ The mechanism of action is multifaceted and includes (1) improved muscle function with less metabolic demand for a given intensity level, (2) lower ventilatory demand which serves to reduce dynamic hyperinflation, (3) desensitization to dyspnea through exertion and possible antidepressant effect of exercise, and (4) education focused on self-management strategies. ${ }^{38}$ Pulmonary rehabilitation is recommended for patients with moderate to very severe COPD. ${ }^{15}$ One therapy for COPD that has been shown to decrease mortality is oxygen therapy for patients with hypoxemia at rest. In patients with COPD and resting hypoxemia, defined as a $\mathrm{PaO}_{2} \leq 60 \mathrm{~mm} \mathrm{Hg}$ and rarely manifests as cold extremities secondary to hypoxic peripheral vasoconstriction, oxygen therapy of two L/min for at least 15 hours daily was associated with a mortality benefit for five years of over $20 \% .{ }^{39}$ Medicare guidelines include continuous oxygen therapy for patients with a resting $\mathrm{PaO}_{2} \leq 55 \mathrm{~mm} \mathrm{Hg}$ or saturation of $\leq 88 \%$. In patients with exertional hypoxemia, ambulatory oxygen therapy may improve six-minute walk performance and dyspnea but it has not been shown to decrease mortality. ${ }^{40}$ Influenza vaccination has been shown to prevent acute respiratory infections in patients with all severities of COPD.${ }^{41}$ In severe cases, a selected group of patients with predominantly upper-lobe emphysema and low exercise capacity have improved functional status and a survival advantage after lung volume reduction surgery. ${ }^{42}$ Lung transplantation may also 
be considered in patients with severely symptomatic COPD to improve quality of life..$^{43}$ Referral to an expert in COPD management is strongly encouraged if surgical treatment options are considered.

Ensuring proper inhaler technique should not be overlooked as a way to improve outcomes in patients with COPD. Up to $54 \%$ of patients have been found to use poor aerosol inhalation technique, a deficiency that can be improved with appropriate training. ${ }^{44,45}$ Fundamentally, metered dose inhalers require a deep, slow inhalation and substantial hand - mouth coordination. Difficulties with coordinating actuation and inhalation are the most commonly reported problems with metered dose inhalers, but they can easily be overcome with the use of a spacer device. ${ }^{46}$ Dry-powder inhalers, in contrast, require a deep forceful inhalation for effective medication delivery. Metered dose inhalers with spacers, dry-powder inhalers, and nebulizers are all equally effective at drug delivery for most patients when used correctly. ${ }^{47}$ Providing appropriate inhaler instructions and observing patients demonstrate that their technique at follow-up clinic visits are keys to assuring patients receive their prescribed doses of medicines. One free online resource for patient educational handouts in English, Spanish, and large print on the variety of inhalers can be found at the American College of Chest Physicians website (http://www.chestnet.org/accp/patient-guides/ patient-instructions-inhaled-devices-english-and-spanish).

\section{Management of comorbidities}

COPD is a systemic disease with many associated comorbidities that often carry greater morbidity and mortality risk than the lung disease itself. One significant class of comorbidities to consider are the psychiatric effects of COPD, which include anxiety, panic attacks, sleep disturbances, and depression. ${ }^{48-50}$ The rates of depression and/or anxiety among COPD patients vary from $20 \%$ to $65 \%$ and increase with acute exacerbations and as the severity of obstruction increases. ${ }^{48,51}$ These comorbidities have a significant negative effect on patient quality of life, functional status, and life-sustaining treatment preferences. Unfortunately, these comorbidities remain undetected, unrecognized, and untreated by clinicians in the majority of patients with COPD. ${ }^{48,50,52}$

There is little evidence evaluating the efficacy of antidepressant and anxiolytic therapy in COPD. In one small, randomized, placebo-controlled trial, the tricyclic antidepressant nortriptyline was shown to significantly improve short-term outcomes for depression, anxiety, distressing physical symptoms (e.g., feeling easily exhausted or suffocated), and overall disability. ${ }^{53}$ In a study of cognitive behavioral therapy (CBT), a single intensive two-hour session resulted in a significant improvement in depressive and anxiety symptoms relative to education only. ${ }^{54}$ In another study comparing CBT with education alone, significant improvements in symptoms were seen in both groups after an 8-week intervention and during subsequent follow up. ${ }^{55}$ Although pharmacologic therapy with tricyclic antidepressants has been proven effective in patients with COPD, newer medications with improved side effect profiles such as selective serotonin reuptake inhibitors (SSRIs) have become the preferred agents. Preliminary data from a small prospective trial suggests that 3 months of SSRI therapy decreases symptoms of depression while improving walking distance and degree of breathlessness. ${ }^{56}$ At our institution, buspirone has been particularly effective for the treatment of COPD-related anxiety. Doses can be rapidly titrated up to a typical maintenance of 10-20 mg 3 times daily with minimal risk of serotenergic syndrome symptoms and abrupt cessation of buspirone does not carry risk of withdrawal. Benzodiazepines can also be effective but they should be used cautiously and only at low doses in patients with preexisting hypercapnia. ${ }^{57}$

Sleep disorders in patients with COPD, especially in those with moderate to severe disease, are common and include insomnia, obstructive sleep apnea (OSA), and restless legs syndrome (RLS) ${ }^{58,59}$ Sleep-maintenance insomnia, in particular, can be attributed to frequent awakenings from coughing, wheezing, and dyspnea. In one study, asymptomatic COPD patients were noted to have significantly less insomnia than those with symptoms. ${ }^{60}$ Optimizing COPD therapy is paramount to treat insomnia in this population. ${ }^{59}$ Sleep produces mild detrimental effects on normal respiratory function which are accentuated in those with COPD. Ten to $20 \%$ of COPD patients suffer from OSA and the coexistence of these conditions is recognized as the Overlap Syndrome. ${ }^{60,61}$ More pronounced daytime hypercapnia, nocturnal hypoxemia, and pulmonary hypertension are present in Overlap Syndrome patients than in those with either disease alone. ${ }^{60,61}$ Optimization of COPD medications, supplemental oxygen therapy, and continuous positive airway pressure (CPAP) are the mainstays of treatment for this condition. Supplemental oxygen therapy has been shown to improve nocturnal hypoxemia and significantly impact the course of pulmonary hypertension, although its effect on sleep quality has yet to be proven. ${ }^{60}$ Commonly, this group of patients will require CPAP, with or without supplemental oxygen. According to the American Academy of Sleep Medicine, patients with COPD are not candidates for autotitrating CPAP devices. ${ }^{62}$ Rather, CPAP therapy at 
a set pressure determined by attended polysomnography is the current recommendation. CPAP has been shown to improve gas exchange, lung function, and respiratory muscle function in those with COPD and OSA, as well as enhance sleep quality. ${ }^{60,63} \mathrm{~A}$ recent study indicates a positive effect of CPAP therapy on survival of patients with moderate to severe Overlap Syndrome. ${ }^{63}$ Finally, there is an increased prevalence of RLS symptoms in COPD; however, the pathophysiologic mechanism remains unclear. ${ }^{64} \mathrm{COPD}$ patients respond to standard dopamine agonist therapy for this condition.

Other nonpulmonary issues that affect patients with COPD include severe malnutrition and osteoporosis. Pulmonary cachexia, defined as weight loss secondary to severe pulmonary disease, affects up to $35 \%$ of patients with moderate to very severe COPD and is an independent predictor of mortality. ${ }^{65}$ Contributing factors include a chronic hypermetabolic state due to the increased work of breathing, tissue hypoxia, and anorexia. Nutritional supplementation has not been shown to improve outcomes alone, but when combined with dietary counseling patients report improvements in quality of life, dyspnea, and functional status. ${ }^{66,67}$ Resting prior to meals and eating small more frequent meals can also improve caloric intake. Osteoporosis affects up to $35 \%$ of COPD patients. ${ }^{68}$ Correlates of this disease include low body mass index, low $\mathrm{FEV}_{1}$, and prior corticosteroid exposure. Treatment follows standard recommendations with bisphosphonates and calcium with vitamin $\mathrm{D}$.

\section{Conclusion}

Reflecting back to our clinical encounter with Mrs B, a 56-year-old female with a long history of tobacco use who was recently diagnosed with severe COPD after experiencing recurrent episodes of shortness of breath resulting in hospitalization. Mrs B also reported complaints of cold hands and insomnia and her husband was concerned that she had become withdrawn. As you may recall, she ascribed her shortness of breath to advancing age, which consequently delayed her initial presentation to the medical community. During her clinic visit, supplemental oxygen was started for her resting hypoxia and within minutes she reported that her hands had finally warmed, reflecting the correction of the rarely seen peripheral vasoconstriction secondary to chronic hypoxemia. Arrangements for continuous home oxygen therapy were made and she was counseled on the importance of wearing oxygen at least 15 hours per day. When Mrs B was asked about her willingness to stop smoking, she stated that she was motivated, but had been trying without success to stop smoking. She reported that she did not want smoking cessation counseling, but was willing to receive pharmacological help to achieve smoking abstinence. Due to the severity of her COPD (severe by GOLD guidelines) and history of multiple exacerbations, the patient was also started on "triple inhaler therapy" with a LAAC and a LABA in combination with an ICS. A spacer device was also provided to be used with her short-acting albuterol. She was instructed by the medical assistant on the proper inhaler technique for all devices and was provided with the patient instructions complete with color pictures from the American College of Chest Physicians website. She agreed to enroll in an 8-week comprehensive pulmonary rehabilitation program, which included exercise training, nutrition counseling, psychological support, and self-management education and then continued to participate in a maintenance program. Finally, she was evaluated by a sleep doctor, underwent polysomnogram, and was started on CPAP for moderate OSA. Upon initial follow up with her case manager, the patient reported getting out of the house more for shopping and dining thanks to reduced symptoms of dyspnea and improved mood. She also reported improved sleep and her husband believes she is more energetic. At her 2-month follow-up visit, Mrs B admitted to restarting smoking after stopping for only 1 week, but that she now smoked only about one half of her previous amount. After discussing and addressing some of the reasons that she started smoking again, she stated that she was willing to try again, this time with the help of a smoking cessation counselor. Her influenza vaccine was updated thanks to an electronic medical record reminder, effective inhaler technique was reviewed, and a bone mineral density scan was ordered to evaluate for possible osteopenia seen on chest X-ray. In addition, she was further counseled on the importance of using her CPAP all night, every night, and during naps. Mrs B had regular contact with her case manager and access to a 24-hour clinic hotline, but she has not yet needed to use the hotline, nearly 6 months after her initial clinic visit.

In summary, COPD is a multisystem disease with significant morbidity and mortality that remains underdiagnosed and undertreated. We have reviewed the evidence-based guidelines for managing this disease including smoking cessation, long-acting bronchodilator therapy, pulmonary rehabilitation, and long-term oxygen therapy for patients with resting hypoxemia. We have also highlighted the importance of the most common comorbid diseases like anxiety, depression, sleep disorders, pulmonary cachexia, and osteoporosis. The complexity of managing COPD and its multiple comorbidities is best addressed with a multifaceted team of providers. The CCM provides the framework for this type of approach by fostering productive interactions between 
informed patients who actively participate in their care and experienced providers who rely both on community resources to provide patient specific education and on technology to ensure compliance with evidence-based treatment guidelines. Successful employment of the CCM shifts the focus from acute management of complications to one of the prevention and is an effective way to improve COPD outcomes.

\section{Disclosure}

The authors David Sonetti and Angela Hospenthal report no conflicts of interest in this work. The author Sandra Adams is an Investigator (also Grant Research) in National Institute of Health (NIH), Veterans Affairs Cooperative Studies Program, Bayer Pharmaceuticals Corp; Boehringer Ingelheim Pharmaceuticals, Inc; Centocor Inc, GlaxoSmithKline; Novartis Pharmaceuticals AG; Pfizer Inc; Schering-Plough Corp. She received Honoraria for Speaking (Unrestricted Grants for Continuing Education, not on any speaker's bureau) in AstraZeneca Pharmaceuticals LP; Bayer Pharmaceuticals Corp; Boehringer Ingelheim Pharmaceuticals, Inc; GlaxoSmithKline; Novartis Pharmaceuticals AG; Pfizer Inc; Schering-Plough Corp.

\section{References}

1. Celli BR, MacNee W, ATS/ERS Task Force. Standards for the diagnosis and treatment of patients with COPD: a summary of the ATS/ERS position paper. Eur Respir J. 2004;23:932-946.

2. National Institutes of Health. National Heart, Lung, and Blood Institute. Morbidity and mortality: 2009 chartbook on cardiovascular, lung, and blood diseases. 2009.

3. Mannino DM, Homa DM, Akinbami LJ, Ford ES, Redd SC. Chronic obstructive pulmonary disease surveillance - United States, 1971-2000. MMWR Surveill Summ. 2002;51:1-16.

4. Jansson SA, Andersson F, Borg S, Ericsson A, Jonsson E, Lundback B. Costs of COPD in Sweden according to disease severity. Chest. 2002;122:1994-2002.

5. Pleis JR, Lethbridge-Cejku M. Summary health statistics for U.S. adults: National Health Interview Survey, 2005. Vital \& Health Statistics Series 10: Data From the National Health Survey. 2006;1-153.

6. Institute of Medicine. Crossing the Quality Chasm: The IOM Health Care Quality Initiative.

7. Wagner EH, Austin BT, Von Korff M. Improving outcomes in chronic illness. Manag Care Q. 1996;4:12-25.

8. Wagner EH. Chronic disease management: what will it take to improve care for chronic illness? Eff Clin Pract. 1998;1:2-4.

9. Wagner EH, Davis C, Schaefer J, Von Korff M, Austin B. A survey of leading chronic disease management programs: are they consistent with the literature? Manag Care Q. 1999;7:56-66.

10. Tsai AC, Morton SC, Mangione CM, Keeler EB. A meta-analysis of interventions to improve care for chronic illnesses. Am J Manag Care. 2005;11:478-488.

11. Adams SG, Smith PK, Allan PF, Anzueto A, Pugh JA, Cornell JE. Systematic review of the components of the chronic care model in the management of chronic obstructive pulmonary disease. Arch Intern Med. 2007;167:551-561.

12. Peytremann-Bridevaux I, Staeger P, Bridevaux PO, Ghali WA, Burnand B. Effectiveness of chronic obstructive pulmonary diseasemanagement programs: systematic review and meta-analysis. $\mathrm{Am} \mathrm{J}$ Med. 2008;121:433-443.e4.
13. Bourbeau J, Collet JP, Schwartzman K, et al. Integrating rehabilitative elements into a COPD self-management program reduces exacerbations and health service utilization: a randomized clinical trial. Am J Respir Crit Care Med. 2000;161:A254.

14. Bourbeau J, Julien M, Maltais F, et al. Reduction of hospital utilization in patients with chronic obstructive pulmonary disease: a disease-specific self-management intervention. Arch Intern Med. 2003;163: 585-591.

15. Global Initiative for Chronic Obstructive Lung Disease (GLOBAL). Global strategy for the diagnosis, management, and prevention of chronic obstructive pulmonary disease: executive summary. Updated edition. 2009.

16. Buist AS, Connett JE, Miller RD, Kanner RE, Owens GR, Voelker HT Chronic Obstructive Pulmonary Disease Early Intervention Trial (Lung Health Study). Baseline characteristics of randomized participants. Chest. 1993;103:1863-1872.

17. Pauwels RA, Rabe KF. Burden and clinical features of chronic obstructive pulmonary disease (COPD). Lancet. 2004;364:613-620.

18. Celli BR, Cote CG, Marin JM, et al. The body-mass index, airflow obstruction, dyspnea, and exercise capacity index in chronic obstructive pulmonary disease. $N$ Engl J Med. 2004;350:1005-1012.

19. Lokke A, Lange P, Scharling H, Fabricius P, Vestbo J. Developing COPD: a 25 year follow up study of the general population. Thorax. 2006;61:935-939.

20. Eisner MD, Balmes J, Katz PP, Trupin L, Yelin EH, Blanc PD. Lifetime environmental tobacco smoke exposure and the risk of chronic obstructive pulmonary disease. Environ Health. 2005;4:7.

21. Balmes J, Becklake M, Blanc P, et al. American Thoracic Society Statement: Occupational contribution to the burden of airway disease. Am J Respir Crit Care Med. 2003;167:787-797.

22. Orozco-Levi M, Garcia-Aymerich J, Villar J, Ramirez-Sarmiento A, Anto JM, Gea J. Wood smoke exposure and risk of chronic obstructive pulmonary disease. Eur Respir J. 2006;27:542-546.

23. Anthonisen NR, Connett JE, Murray RP. Smoking and lung function of Lung Health Study participants after 11 years. Am J Respir Crit Care Med. 2002;166:675-679.

24. Kanner RE, Connett JE, Williams DE, Buist AS. Effects of randomized assignment to a smoking cessation intervention and changes in smoking habits on respiratory symptoms in smokers with early chronic obstructive pulmonary disease: the Lung Health Study. Am J Med. 1999;106:410-416.

25. Combivent Inhalation Aerosol Study Group. In chronic obstructive pulmonary disease, a combination of ipratropium and albuterol is more effective than either agent alone. An 85-day multicenter trial. COMBIVENT Inhalation Aerosol Study Group. Chest. 1994;105: 1411-1419.

26. O'Donnell DE, Fluge T, Gerken F, et al. Effects of tiotropium on lung hyperinflation, dyspnoea and exercise tolerance in COPD. Eur Respir J. 2004;23:832-840.

27. Tashkin DP, Celli B, Senn S, et al. A 4-year trial of tiotropium in chronic obstructive pulmonary disease. N Engl J Med. 2008;359:1543-1554.

28. Calverley PM, Anderson JA, Celli B, et al. Salmeterol and fluticasone propionate and survival in chronic obstructive pulmonary disease. N Engl J Med. 2007;356:775-789.

29. Aaron SD, Vandemheen KL, Fergusson D, et al. Tiotropium in combination with placebo, salmeterol, or fluticasone-salmeterol for treatment of chronic obstructive pulmonary disease: a randomized trial. Ann Intern Med. 2007;146:545-555.

30. Decramer M, de Bock V, Dom R. Functional and histologic picture of steroid-induced myopathy in chronic obstructive pulmonary disease. Am J Respir Crit Care Med. 1996;153:1958-1964.

31. Camner P, Mossberg B, Philipson K, Strandberg K. Elimination of test particles from the human tracheobronchial tract by voluntary coughing. Scand J Respir Dis. 1979;60:56-62.

32. Hasani A, Pavia D, Agnew JE, Clarke SW. Regional lung clearance during cough and forced expiration technique (FET): effects of flow and viscoelasticity. Thorax. 1994;49:557-561.

33. Decramer M, Rutten-van Molken M, Dekhuijzen PN, et al. Effects of N-acetylcysteine on outcomes in chronic obstructive pulmonary disease (Bronchitis Randomized on NAC Cost-Utility Study, BRONCUS): a randomised placebo-controlled trial. Lancet. 2005;365:1552-1560. 
34. Poole PJ, Black PN. Mucolytic agents for chronic bronchitis or chronic obstructive pulmonary disease. Cochrane Database of Syst Rev. 2006;3:CD001287.

35. McCool FD. Global physiology and pathophysiology of cough: ACCP evidence-based clinical practice guidelines. Chest. 2006;129:48S-53S.

36. Ries AL. Position paper of the American Association of Cardiovascular and Pulmonary Rehabilitation. Scientific basis of pulmonary rehabilitation. J Cardiopulm Rehabil. 1990;10:418-441.

37. Nici L, Donner C, Wouters E, et al. American Thoracic Society/European Respiratory Society statement on pulmonary rehabilitation. Am J Respir Crit Care Med. 2006;173:1390-1413.

38. Casaburi R, ZuWallack R. Pulmonary rehabilitation for management of chronic obstructive pulmonary disease. $N$ Engl J Med. 2009;360: 1329-1335.

39. Report of the Medical Research Council Working Party. Long term domiciliary oxygen therapy in chronic hypoxic cor pulmonale complicating chronic bronchitis and emphysema. Report of the Medical Research Council Working Party. Lancet. 1981;1:681-686.

40. Crockett AJ, Cranston JM, Moss JR, Alpers JH. Domiciliary oxygen for chronic obstructive pulmonary disease. Cochrane Database Syst Rev. 2000;CD001744.

41. Wongsurakiat P, Maranetra KN, Wasi C, Kositanont U, Dejsomritrutai W, Charoenratanakul S. Acute respiratory illness in patients with COPD and the effectiveness of influenza vaccination: a randomized controlled study. Chest. 2004;125:2011-2020.

42. Fishman A, Martinez F, Naunheim K, et al. A randomized trial comparing lung-volume-reduction surgery with medical therapy for severe emphysema. N Engl J Med. 2003;348:2059-2073.

43. Patel N, DeCamp M, Criner GJ. Lung transplantation and lung volume reduction surgery versus transplantation in chronic obstructive pulmonary disease. Proc Am Thorac Soc. 2008;5:447-453.

44. Cochrane MG, Bala MV, Downs KE, Mauskopf J, Ben-Joseph RH. Inhaled corticosteroids for asthma therapy: patient compliance, devices, and inhalation technique. Chest. 2000;117:542-550.

45. Al-Showair RA, Tarsin WY, Assi KH, Pearson SB, Chrystyn H. Can all patients with COPD use the correct inhalation flow with all inhalers and does training help? Respir Med. 2007;101:2395-2401.

46. Broeders ME, Sanchis J, Levy ML, Crompton GK, Dekhuijzen PN, ADMIT Working Group. The ADMIT series - issues in inhalation therapy. 2. Improving technique and clinical effectiveness. Prim Care Respir J. 2009;18:76-82.

47. Dolovich MB, Ahrens RC, Hess DR, et al. Device selection and outcomes of aerosol therapy: evidence-based guidelines: American College of Chest Physicians/American College of Asthma, Allergy, and Immunology. Chest. 2005;127:335-371.

48. Kunik ME, Roundy K, Veazey C, et al. Surprisingly high prevalence of anxiety and depression in chronic breathing disorders. Chest. 2005;127:1205-1211.

49. van Ede L, Yzermans CJ, Brouwer HJ. Prevalence of depression in patients with chronic obstructive pulmonary disease: a systematic review. Thorax. 1999;54:688-692.

50. Yohannes AM, Baldwin RC, Connolly MJ. Depression and anxiety in elderly patients with chronic obstructive pulmonary disease. Age Ageing. 2006;35:457-459.

51. Coultas DB, Edwards DW, Barnett B, Wludyka P. Predictors of depressive symptoms in patients with COPD and health impact. COPD: J Chron Obstruct Pulmon Dis. 2007;4:23-28.

Journal of Multidisciplinary Healthcare

\section{Publish your work in this journal}

The Journal of Multidisciplinary Healthcare is an international, peerreviewed open-access journal that aims to represent and publish research in healthcare areas delivered by practitioners of different disciplines. This includes studies and reviews conducted by multidisciplinary teams as well as research which evaluates the results or conduct of such teams or Submit your manuscript here: http://www.dovepress.com/journal-of-multidisciplinary-healthcare-journal
52. Williams JW Jr, Mulrow CD, Kroenke K, et al. Case-finding for depression in primary care: a randomized trial. Am J Med. 1999;106:36-43.

53. Borson S, McDonald GJ, Gayle T, Deffebach M, Lakshminarayan S, VanTuinen C. Improvement in mood, physical symptoms, and function with nortriptyline for depression in patients with chronic obstructive pulmonary disease. Psychosomatics. 1992;33:190-201.

54. Kunik ME, Braun U, Stanley MA, et al. One session cognitive behavioural therapy for elderly patients with chronic obstructive pulmonary disease. Psychol Med. 2001;31:717-723.

55. Kunik ME, Veazey C, Cully JA, et al. COPD education and cognitive behavioral therapy group treatment for clinically significant symptoms of depression and anxiety in COPD patients: a randomized controlled trial. Psychol Med. 2008;38:385-396.

56. Eiser N, Harte R, Spiros K, Phillips C, Isaac MT. Effect of treating depression on quality-of-life and exercise tolerance in severe COPD. COPD: J Chron Obstruct Pulmon Dis. 2005;2:233-241.

57. Maurer J, Rebbapragada V, Borson S, et al. Anxiety and depression in COPD: current understanding, unanswered questions, and research needs. Chest. 2008;134:43S-56S.

58. Urbano F, Mohsenin V. Chronic obstructive pulmonary disease and sleep: the interaction. Panminerva Med. 2006;48:223-230.

59. Sharafkhaneh A, Jayaraman G, Kaleekal T, Sharafkhaneh H, Hirshkowitz M. Sleep disorders and their management in patients with COPD. Ther Adv Respir Dis. 2009;3:309-318.

60. Bhullar S, Phillips B. Sleep in COPD patients. J Chron Obstruct Pulmon Dis. 2005;2:355-361.

61. Lopez-Acevedo MN, Torres-Palacios A, Elena Ocasio-Tascon M, Campos-Santiago Z, Rodriguez-Cintron W. Overlap syndrome: an indication for sleep studies?: A pilot study. Sleep Breath. 2009;13:409-413.

62. Morgenthaler TI, Aurora RN, Brown T, et al. Practice parameters for the use of autotitrating continuous positive airway pressure devices for titrating pressures and treating adult patients with obstructive sleep apnea syndrome: an update for 2007. An American Academy of Sleep Medicine report. Sleep. 2008;31:141-147.

63. Machado MC, Vollmer WM, Togeiro SM, et al. CPAP and survival in moderate-to-severe obstructive sleep apnoea syndrome and hypoxaemic COPD. Eur Respir J. 2010;35:132-137.

64. Lo Coco D, Mattaliano A, Lo Coco A, Randisi B. Increased frequency of restless legs syndrome in chronic obstructive pulmonary disease patients. Sleep Medicine. 2009;10:572-576.

65. Chailleux E, Laaban JP, Veale D. Prognostic value of nutritional depletion in patients with COPD treated by long-term oxygen therapy: data from the ANTADIR observatory. Chest. 2003;123:1460-1466.

66. Ferreira IM, Brooks D, Lacasse Y, Goldstein RS, White J. Nutritional supplementation for stable chronic obstructive pulmonary disease. Cochrane Database Syst Rev. 2002;CD000998.

67. Weekes CE, Emery PW, Elia M. Dietary counselling and food fortification in stable COPD: a randomised trial. Thorax. 2009;64:326-331.

68. Graat-Verboom L, Wouters EF, Smeenk FW, van den Borne BE, Lunde R, Spruit MA. Current status of research on osteoporosis in COPD: a systematic review. Eur Respir J. 2009;34:209-218. healthcare processes in general. The journal covers a wide range of areas and welcomes submission from practitioners at all levels, from all over the world. The manuscript management system is completely online and includes a very quick and fair peer-review system. Visit http://www.dovepress.com/testimonials.php to read real quotes from published authors. 